\title{
Defining and classifying public health systems: a critical interpretive synthesis
}

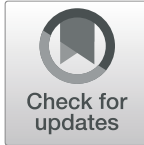

Tamika Jarvis ${ }^{1 *}\left(\mathbb{D}\right.$, Fran Scott $^{1 \dagger}$, Fadi El-Jardali ${ }^{1,2+}$ and Elizabeth Alvarez ${ }^{1 \dagger}$

\begin{abstract}
Background: The introduction of the determinants of health has caused a shift towards understanding health from a holistic perspective as well as increased recognition of public health's contributions to the health of the population. Several frameworks exist to conceptualise healthcare systems, highlighting the stark contrast of frameworks unique to public health systems. The objectives of this study were to define public health systems and assess differences between healthcare systems and public health systems within established health systems frameworks.

Methods: A critical interpretive synthesis was conducted. Databases searched included EBSCOhost, OVID, Scholars Portal, Web of Science, Cochrane Library and Health Systems Evidence. Data extraction, coding and analysis followed a best-fit framework analysis method. Initial codes were based on a current leading health systems and policy classification scheme - health systems arrangements (governance, financial and delivery arrangements).

Results: A total of 5933 unique documents were identified and 67 were included in the analysis. Definitions of public health and public health systems varied significantly as did their roles and functions across jurisdictions. Public health systems arrangements generally followed those of health systems, with the addition of partnerships (community and inter-sectoral) and communication playing a larger role in public health. A public health systems framework and conceptualisation of how public health currently fits within health systems are presented.

Conclusions: Public health systems are unique and vital entities within health systems. In addition to examining how public health and public health systems have been defined within the literature, this review suggests that establishing the scope of public health is crucial to understanding its role within the larger health system and adds to the discourse around the relationship between public health, healthcare and population health. More broadly, this study addresses an important gap in understanding public health systems and provides conceptual and practical contributions as well as areas for future research.
\end{abstract}

Keywords: Public health, Health systems, Population health, Health services

\section{Background}

Public health is generally understood to engage in population rather than in individual health activities and to undertake a population health approach recognising that genetic, behavioural and socio-economic factors (e.g. housing, social networks, education) influence health and

\footnotetext{
* Correspondence: jarvistl@mcmaster.ca

${ }^{\dagger}$ Fran Scott, Fadi El-Jardali and Elizabeth Alvarez contributed equally to this work.

'Department of Health Research Methods, Evidence and Impact (HEl),

McMaster University, 1280 Main Street West, Hamilton, ON L8S 4K1, Canada Full list of author information is available at the end of the article
}

well-being $[1,2]$. The introduction of the determinants of health has caused a shift towards understanding health from a holistic perspective as well as increased recognition of public health's contributions to the health of the population [3]. Outside of global public health emergencies, such as Ebola or Zika Virus, attention to the role that public health plays in the protection and advancement of health has often taken a backseat to discussions of healthcare reform $[4,5]$. For many, health and the health system equate to healthcare, namely clinics and hospitals. In the context of the United States and Canada, considering, for example, that medical care consumes the largest amounts

(c) The Author(s). 2020 Open Access This article is licensed under a Creative Commons Attribution 4.0 International License, which permits use, sharing, adaptation, distribution and reproduction in any medium or format, as long as you give appropriate credit to the original author(s) and the source, provide a link to the Creative Commons licence, and indicate if changes were made. The images or other third party material in this article are included in the article's Creative Commons licence, unless indicated otherwise in a credit line to the material. If material is not included in the article's Creative Commons licence and your intended use is not permitted by statutory regulation or exceeds the permitted use, you will need to obtain permission directly from the copyright holder. To view a copy of this licence, visit http://creativecommons.org/licenses/by/4.0/ The Creative Commons Public Domain Dedication waiver (http://creativecommons.org/publicdomain/zero/1.0/) applies to the data made available in this article, unless otherwise stated in a credit line to the data. 
of the health budget in Canada and the United States, it is unsurprising that there is generally little public or political interest in strengthening or investing in public health systems [6, 7]. For example, amid concerns that public health across Canada continues to be weakened through budgetary cuts and lack of investment in public health infrastructure, there remains little evidence related to understanding public health systems or what is currently done in practice in a comparative fashion $[6,8]$. Most public health research has focused on the evaluation of programmes aimed at individual or population-level interventions and understanding the causes and patterns of risk of ill health and disease rather than informing broader questions about the organisation, delivery or funding mechanisms of public health systems [7, 9-11]. Amid the current novel coronavirus disease (COVID-19) pandemic, understanding how public health and broader health systems function, is crucial.

Health services and system researchers have not adequately acknowledged public health as a vital component and contributor to health systems, and achievements made by public health activities, such as communicable and non-communicable disease control, are often attributed to the delivery of primary healthcare services and advances in biomedical interventions [12]. While multiple health systems frameworks identify the components, functions and goals of healthcare systems, no clear or consistent definition of public health systems exist [13, 14].

Defining public health systems can help determine how to best design systems and deliver programmes and services to support public health within the larger health system and other key institutions and move discussions about the relationship between public health and healthcare forward. As a first step, this paper addresses a priority research area that called for the development of a framework describing the key elements of public health systems $[3,15,16]$. A qualitative synthesis of the current literature was completed to investigate how public health systems have been defined and classified as well as the differences between healthcare systems and public health systems within established conceptual frameworks for health systems.

\section{Methods}

This qualitative review adopted the critical interpretive synthesis (CIS) approach as the overarching methodology while using a second and complimentary qualitative strategy, the best-fit framework synthesis (BFF), to guide structured data extraction and analysis. CIS differs from traditional systematic reviews in several ways; namely, (1) it is an iterative process that explicitly allows for the critical re-interpretation of existing literature and filling of conceptual gaps, and (2) it prioritises the inclusion of papers based on relevance to the research question, including grey literature, increasing the likelihood of capturing relevant documents [17-19]. The BFF is used to test, refine and/or generate relevant frameworks, theories or conceptual models using systematically retrieved empirical data. For this study, BFF was determined to be useful for the organisation, extraction and analysis of large amounts of data, as a priori or pre-identified codes allows researchers to utilise and generate codes and interpret themes but not be restricted by an existing framework, model or theory [20]. This study conformed with the recommended PRISMA guidelines [21] and was registered in PROSPERO (CRD42016049967).

\section{Search strategy}

Following pilot testing, the databases searched included EBSCOhost, OVID, Scholars Portal, Web of Science, Cochrane Library and Health Systems Evidence. The final search was conducted on 25 October 2016. Studies were not limited to date, language or study design. Additional sources were identified through reviewing the references of included documents to find relevant material and through internet searching to fill conceptual gaps using non-systematic searching. The initial search strategy can be found in Additional file 1. As public health systems have not been clearly defined, our search strategy sought to include terms that may be used interchangeably within the literature but warrant clear definitions. For the purpose of this study, we define a system as " $a$ set of inter-connected parts that have to function together to be effective" [22], a framework as "a basic conceptual structure" [23], a model as "a standard or example for imitation for comparison" [24], and classification as "an arrangement of people or things into groups based on ways that they are alike" [25].

\section{Study selection}

Records identified were screened, duplicates were removed, and titles and abstracts were independently reviewed for exclusion by two reviewers. Records were excluded that (1) did not describe local, state/provincial/ territorial, or national public health systems, frameworks or critical components, (2) addressed publicly funded healthcare systems, unless it also addressed the role of public health, and (3) were in languages other than English, French or Spanish. Records were not restricted by date or country as we wanted to obtain a general picture of public health systems globally. To help address the compass question and maximise the diversity of papers, potentially relevant documents were purposively sampled and prioritised for inclusion if they were clearly relevant to the research topic, offered conceptual insights about full frameworks, and were able to provide a cross section of different jurisdictions [19, 26]. Full-text 
documents were retrieved and assessed for eligibility with additional documents found through reference chaining of all included studies or internet searches to help fill conceptual gaps.

\section{Data abstraction}

A data extraction tool was developed to organise the key themes of relevant documents and bibliographic information, including title of document, author(s), study type, context of study, key topic areas, and further relevant references from paper. Documents were imported into NVivo 11 software to facilitate the coding and organisation of data. Seven documents were randomly selected and coded independently by two reviewers to ensure consistency. Disagreements were resolved by consensus.

\section{Data analysis and synthesis}

A current leading health systems and policy classification scheme, the health systems arrangements framework (based on the three key building blocks of governance, financial and delivery arrangements), was used to form the initial a priori codes [27]. Originally developed as a taxonomy of health system topics to classify documents for Health Systems Evidence, this framework was chosen as the BFF theoretical framework because it is comprehensive (e.g. includes the essential components of WHO's health system building blocks [22]), easy to understand, and has been used in various international contexts for health systems and policy research and applied work, for example, to develop health systems guidance documents and to contextualise research for evidence-based decisionmaking in Peru and Uganda [28-30]. Codes were added inductively from the data and were linked into themes. Data analysis continued until there was data saturation and conceptual gaps were addressed [31].

\section{Results}

\section{Search results and study selection}

Electronic database searches identified 5933 unique citations, 338 of which met inclusion criteria after title and abstract exclusion; 81 of these documents were purposively sampled and full-text review excluded 23 records. Nine additional documents were attained through reference chaining and internet searches. In total, 67 documents were included (Fig. 1). A description of these documents can be found in Additional file 2 .

The results are presented in four sections - defining public health and public health systems; roles and functions of public health; public health systems; and public health within health systems. High-level findings are presented in the text and more details are provided in the Additional files.

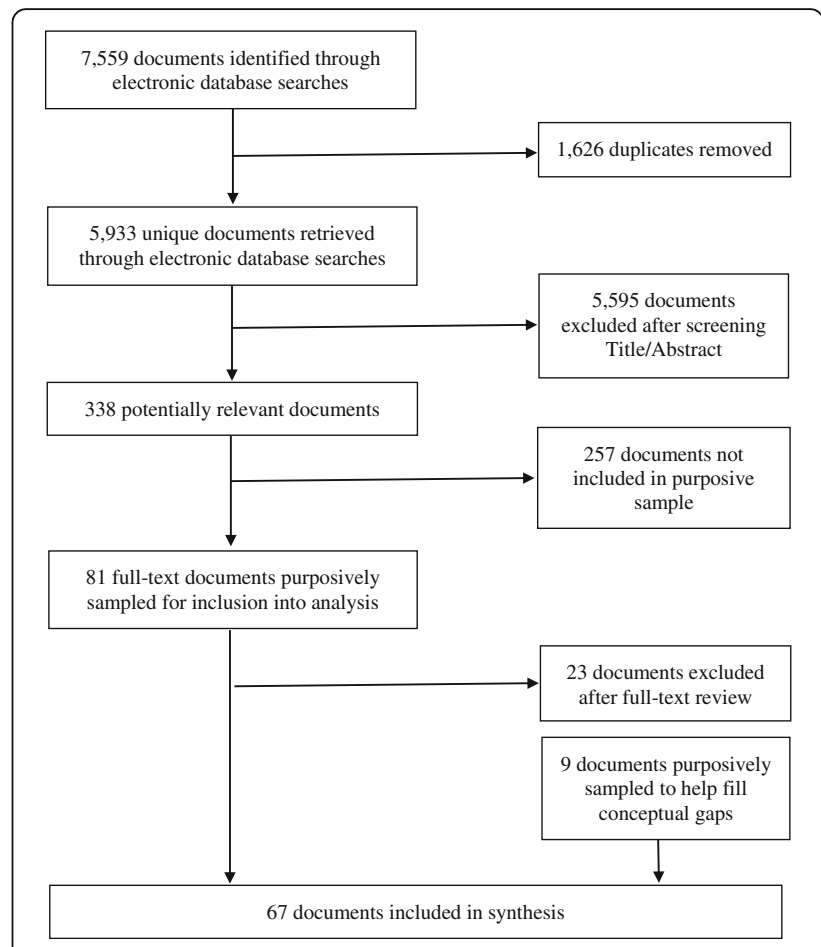

Fig. 1 PRISMA flow chart for inclusion/exclusion of documents [21]

Defining public health and public health systems

Most documents defined public health via its functions; therefore, separate sections were created for defining public health and public health systems and for describing the roles and functions of public health.

\section{Public health}

Seven definitions of public health were found (Additional file 3). Public health was described as a multidisciplinary area of practice, concept and set of values that engaged in a larger population health perspective. Eight documents used the definition of public health provided by $\mathrm{WHO}$ as an art and science whose organised efforts aim to prevent illness and disease as well as to protect and promote health within society [32-39]. Five other definitions expanded or emphasised various priorities within public health practice and included values of equity and equality.

\section{Public health systems}

Public health systems were defined in 20 documents, with 10 unique definitions identified (Additional file 3). Eleven documents defined public health systems as all levels of governmental and non-governmental entities which share in the responsibility for ensuring healthy social and physical environments, and consist of a variety of organisations that contribute to the core functions of public health to protect and promote health within the community [12, 40-49]. Public health systems 
were also defined based on their composition, level of service, contributing actors, mission and activities, or a combination of these. Public health was largely seen as a governmental responsibility and included partnerships between formal (government) and informal (private sectors, volunteer) organisations.

\section{Roles and functions of public health Frameworks}

Subsystem models of delivery, governance, finance, and roles and functions were identified, for example, Mays et al.'s [45] typology of public health delivery systems, but none provided a comprehensive public health system framework. Several frameworks identified essential public health functions (Additional file 4). The most frequent frameworks were the Institute of Medicine's three 'core' public health functions of assessment, policy development and assurance [12, 38, 42, 47, 48, 50] and the 'Ten Essential Public Health Services', which were developed to further refine the specific set of functions and services within public health systems in the United States but have been adapted elsewhere [40, 42, 44, 48, 51-56].

\section{Roles and functions}

Thirty-nine documents defined or highlighted what they identified as the 'essential' functions of public health. Additional file 4 provides a table as a way of organising what functions were found within the literature across a variety of countries, following the three core public health functions and 10 essential services. The following were listed as public health functions and services in more than half of the documents: health promotion $(n=$ 30 ); health protection, which included air, water, and food quality and inspection as well as environmental and occupational health activities $(n=26)$; investigation and surveillance $(n=25)$; emergency planning, preparedness and response $(n=25)$; health assessment and monitoring $(n=24)$; injury and chronic disease prevention and management $(n=23)$; and linking with and providing personal clinical services, which included maternal and child health services, minority, rural, indigent, mental, clinical and community health improvement activities, to targeted and/or vulnerable populations $(n=22)$. Communicable disease control $(n=18)$; research $(n=16)$; regulation and enforcement $(n=16)$; resource and organisational management, including leadership, governance capacity, resource management and development of organisational structures $(n=14)$; establishment of partnerships and advocacy in communities $(n=13)$; evaluation of health services $(n=11)$; policy development and planning $(n=11)$; workforce strengthening $(n=9)$; programme implementation $(n=4)$; laboratory services $(n=3)$; hospital and long-term care facility licensing $(n=2)$; and vital statistics $(n=2)$ were also identified as being the responsibility of public health in various jurisdictions. Functions and services had to be interpreted and summarised, as there were different terms being used to represent the same activities between jurisdictions. For example, health protection and environmental health were both used to describe the responsibility for testing and monitoring the quality of air, food and water, and population health assessment was used to describe monitoring, surveillance or epidemiological activities.

\section{Public health systems}

It was found that public health system descriptions fit the health system arrangements framework well, with the addition of partnerships and communication, which affected each of the other parts of the system (Additional file 5). The health systems arrangements framework was refined to highlight differences between terms and components of public health systems (Table 1). While little to no evidence on certain features, such as commercial authority, remunerating providers and incentivising consumers, was available within the literature, these arrangements are still applicable to public health, and thus remain within the public health systems framework.

\section{Governance arrangements}

Policy authority Four levels of policy authority were identified within the public sector, namley international, national, state/provincial/territorial, and local. The degree

Table 1 Public health system arrangements, adapted from health system arrangements framework

\begin{tabular}{|c|c|c|}
\hline Key features & & \\
\hline Partnerships and & Governance & Policy authority \\
\hline Communication & arrangements & Organisational authority \\
\hline & & Commercial authority \\
\hline & & Professional authority \\
\hline & & $\begin{array}{l}\text { Consumer and stakeholder } \\
\text { involvement }\end{array}$ \\
\hline & Financial & Financing systems \\
\hline & arrangements & Funding organisations \\
\hline & & Remunerating providers \\
\hline & & Purchasing products and services \\
\hline & & Incentivising consumers \\
\hline & $\begin{array}{l}\text { Delivery } \\
\text { arrangements }\end{array}$ & $\begin{array}{l}\text { How are programmes and services } \\
\text { designed to meet consumers' needs }\end{array}$ \\
\hline & & $\begin{array}{l}\text { By whom are programmes and } \\
\text { services provided }\end{array}$ \\
\hline & & $\begin{array}{l}\text { Where are programmes and services } \\
\text { provided }\end{array}$ \\
\hline & & $\begin{array}{l}\text { With what supports are programmes } \\
\text { and services provided }\end{array}$ \\
\hline
\end{tabular}


of decentralisation within a country or state/province determined the responsibilities and structural organisation of agencies within public health systems [4, 12, 32, 34, 37, 44, 46, 49, 57-60]. Most national public health agencies were primarily responsible for providing guidance and acting as a source of expertise while giving states/provinces authority to organise public health $[4,32,39,48,54,57$, 61-64]. Many state/provincial governments established overall priorities, strategic direction, policies, strategies, standards, and funding models for local public health agencies [4, 34].

Organisational authority Regional or local health units planned and implemented the majority of services, developed policies and communicated legislation [34, 57, $61,63,65]$.

Consumer and stakeholder involvement In public health systems, consumers most often referred to targeted populations and communities rather than individuals, as is more common in healthcare systems. Stakeholders included other public sectors, communities, service providers in and outside of the health system, the private sector, and individuals [63]. Community partnerships and public engagement were identified as being important for individual and community health, accountability, and an influential factor in the operation of local public health agencies [33, 41, 47, 56, 61, 63, 66, 67].

\section{Delivery arrangements}

In public health systems, the terms 'programmes' or 'services' seemed to better reflect the wide range of activities and roles of public health within the larger health system than the term 'care'.

How are programmes and services designed to meet consumers' needs Public health functions were carried out by all levels of government, including federal, state/ provincial/territorial and local, but most activities remained organised at the state/provincial level or locally in many countries [2, 38-40, 48, 58, 59, 62, 63, 68-71]. Delivery of public health services often rested at the local level but, in some instances, were delivered at the state/provincial level or through separate government or private organisations [38, 48, 59, 62]. In one United States-based example, although public health and healthcare were largely independent of one another, public health increasingly provided personal health services for pre-identified or vulnerable groups [72].

By whom are programmes and services provided Most public health programmes/services were provided by public sector employees as part of a public health unit, as well as faith-based groups, private businesses, social services agencies, schools, workplaces and healthcare providers $[46,73]$. Healthcare and other sectors support public health in its missions by participating in surveillance, health protection and emergency planning activities [37, 73, 74]. Because of the diversity in the organisations and people involved in providing public health programmes and services, the size of a public health workforce is difficult to determine $[5,57,63,73,75]$.

Where are programmes and services provided Delivery of public health programmes and services occurs in multiple public and private settings, including schools, homes of private citizens, workplaces, clinics, public health laboratories, local public health agencies and offices, and various indoor and outdoor spaces within the community $[57,61]$. Partnerships and contracts with non-governmental and community organisations in public and private sectors have often been established to circumvent barriers to service provision (e.g. due to geographical location or size of jurisdictions) $[40,49,71]$.

With what supports are programmes and services provided Support was often referred to as capacity in human health resources [2, 40, 51, 57, 59] and information technology $[62,75]$. A few articles discussed the use of technology as a tool used to deliver and support public health activities and messaging, and included services such as eHealth, web portals, mobile phone applications and social media [66].

\section{Financial arrangements}

It was difficult to estimate the direct and indirect financial contributions by public and private sectors given the diversity in public health activities [39].

Financing systems Several sources estimated that, on average, public health systems received between $3 \%$ and $8 \%$ of the national health budget $[5,32,38,39,44,51$, 57, 72]. Like healthcare, public and private funding sources existed in these systems, with many being publicly financed through general taxation, including federal, state/provincial and local taxes such as income, property and sales taxes [32, 39, 47, 52, 57-59, 62, 69, 76]. Private sector financing included out-of-pocket service fees and for-profit and non-profit organisations [44, 47, 52, 59]. A significant part of public health funding is derived from external donors, particularly for disease-specific initiatives, in low-income countries [58].

Funding organisations Revenue transfers from national governments to state/provincial or local public health agencies, with funding being distributed to local health agencies to deliver services, were most prevalent. Funding was largely allocated by funding formulas; however, 
a combination of funding mechanisms, such as activityand standard-specific funding and reimbursements, per capita allocations, competitive and needs-based grants, and performance-based funding were also reported [38, $46,47,55,58,59]$. Other sources of funding originated from other public sector partners and from collaborations between public and private sectors [39, 47, 59, 65]. In some instances, external donors allocated funds to community-based organisations to target specific community health needs or provided informal funding for 'nonessential' public health programmes [4, 12, 39, 47, 63, 65].

Purchasing products and services Funding organisations and purchasing products and services were strongly linked. Many federal and state/provincial governments allocated funds for specific public health activities, which influenced the availability of services [38, 46, 47, 58, 59]. Generally, there was a trend towards a substantial portion of public health funding directed at individual clinical services (e.g. maternal and child health, mental health, prenatal visits, family planning) $[12,60]$.

\section{Partnerships and communication}

Partnerships were identified as an essential way to extend the reach of programmes to target population health issues and to share expertise, information and resources $[2,4,39,40,46,56,59,65,66,68,77-81]$. Partners included other local, national and international government agencies, the healthcare system, academic centres, private sector businesses, faith groups, foundations, service organisations and communities [32-34, 40, $45,46,48,52,54,56,62-64,72,79,82,83]$. Within governance arrangements, the goal of partnerships was identified as community empowerment and capacitybuilding for successful interventions $[4,56,61,74,79$, 82, 84]. Engagement within communities reportedly increased stakeholder involvement in policy and decisionmaking [82, 84].

Public health is an information-dependent sector that requires constant information exchange in order to support public health functions, activities and policies, especially in emergency planning and response [2, 58]. Communication not only improves surveillance and response systems between all levels of government and internationally but is necessary for effective knowledge translation activities [5, 84, 85]. Clear, consistent and timely communication is essential for delivering messages to the public, preventing mixed messages and encouraging public engagement. Current and evolving technology, such as the internet and other mass media sources, are tools that support this effort by improving health literacy and outreach [66] but can also spread misinformation.

\section{Public health within health systems}

In framing how public health is seen as part of a larger health system, the literature pointed to two related but separate concepts - that of system integration and the role of public health in promoting a population health approach.

Sofaer [79] states that the best way to judge how effective a health system is, is by how well it can improve the health of individuals and populations. Interest in integrating public health and healthcare systems is not new [34, 48, 76]. While definitions of integration vary, integration in this report is the relationship between public health and healthcare and the extent to which services are provided to promote and achieve health. Integration is believed to bring the two systems closer together to provide a seamless service delivery within the larger health system and better respond to the needs of both individuals and communities [33, 65]. Potential benefits of integration include bringing a population health perspective to the healthcare system, increased access to care, and the reduction of direct and indirect healthcare costs [4]. However, the literature also points to various challenges regarding integration and what it might mean for the future of the public health system. These include the loss of public health authority and expertise, capacity and management of competing priorities, consequently linked to adverse health outcomes [58]. Over time, the diversion of public health resources to primary care, loss of positions in public health units, and loss of linkages to community partners and communities would hinder public health from being able to extend the reach of its activities and lead to fragmentation in programme delivery and in the services necessary to protect the health of the population such as community health assessments, programme planning, and disease control and surveillance $[9,58,86]$.

From the literature, healthcare and public health are separate systems, often with their own aims and functions, governance and financial systems, and ways of delivering services, although significant overlap has been observed, particularly within delivery arrangements. The health system is separate from but influenced by the larger political and social systems. Health, within this health system, is determined by individual factors and access to and use of public health and healthcare services. Yet, the wider determinants of health recognise the importance of social and political factors on health. Figure 2 aims to organise how public health currently fits within a health system. It is important to note that public health is often equated to and touted as a steward of population health. Population health is the driving force behind public health. Its upstream focus, following an ecological model of health, is concerned with how individual, social and environmental determinants influence 


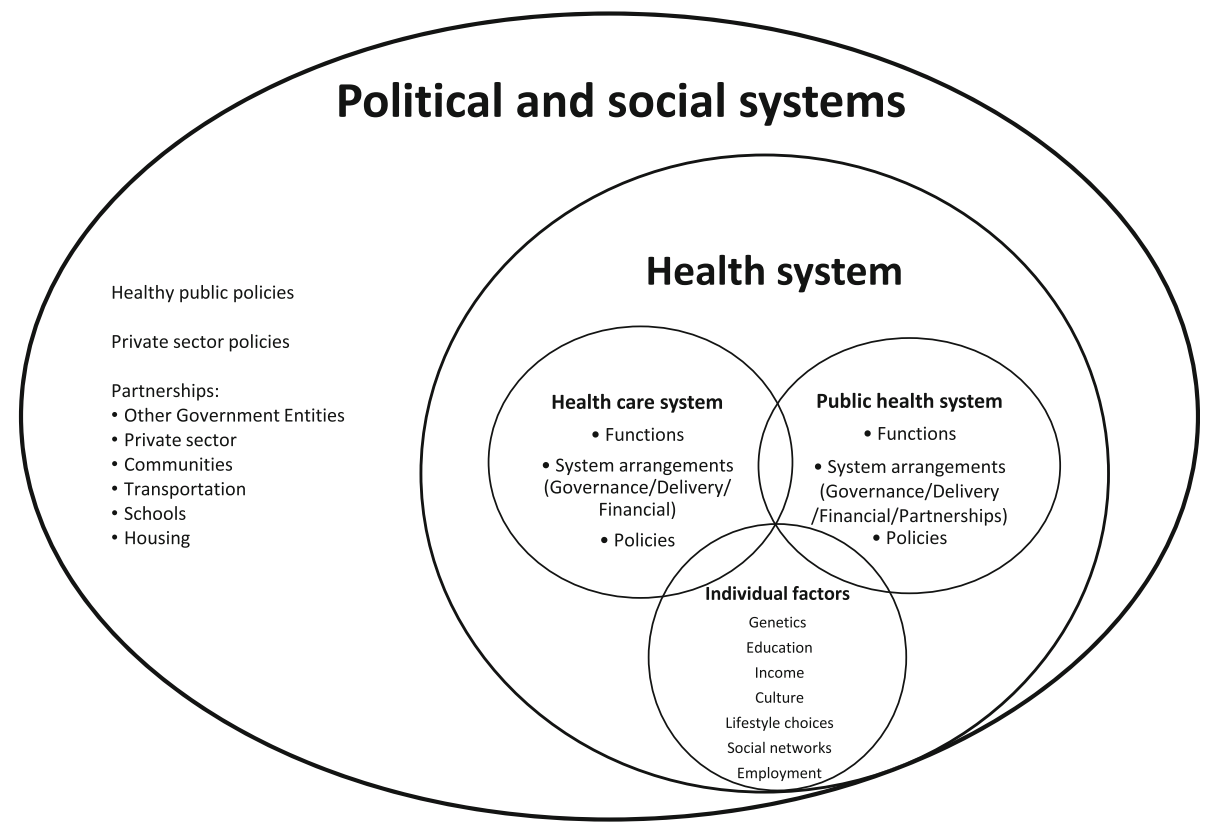

Fig. 2 Conceptual fit of public health systems within current health systems

health outcomes $[53,55]$. A strength of the population health approach is that it recognises that people are not passive but are active participants in their own health outcomes. Individual health is supported by both public health and healthcare activities and by how individuals interact with these systems and their larger social environments. There is a constant exchange between individuals, healthcare, public health, and the political and social systems they are embedded in, with more resources, programmes and services targeted towards those identified as vulnerable to try and establish a level of equity in health outcomes. It could be argued that, while activities in public health are population based, the ultimate target of public health is still to support individual health within the larger community. For example, although health promotion messages and activities are delivered to the population, the goal of these activities is to encourage individuals within communities towards healthier lifestyles (e.g. tobacco cessation, vaccinations), whose health statistics are then tracked (e.g. surveillance) and regarded as the population's health.

Population health is conceptualised as extending far beyond the health system to include the political and societal contexts. While policies outside of the public health system may not be implemented to directly impact population health, they often do. For example, taxes on carbon emissions have short- and long-term effects on population-level health outcomes. Similarly, public health systems affect, and are affected by, many sectors. As broader determinants of health are becoming increasingly recognised as influential, there has been an increased emphasis on holistic approaches to healthy public policies [9]. Recent work has focused on holistic approaches to health such as Health in All Policies and One Health. Health in All Policies refers to the intersectoral aim of integrating health considerations into the actions, interventions and policies outside of the health sector, and One Health refers to the approach that recognises that human health is influenced by both animal and environmental health [87, 88]. Figure 2 highlights the gaps that exist between what we currently have, at least in high-income countries, and paradigms of population health, Health in All Policies and, especially, One Health. For example, public health is often separate from healthcare and from the political process (i.e. healthy public policies). Population health spans further than public health's reach and integration may need to be reconceptualised to align with a broader vision of health.

\section{Discussion}

\section{Main findings}

The synthesis suggests that public health systems have not been clearly defined because (1) public health systems have been conceptualised in various ways and (2) there is overlap in terminology with publicly funded healthcare systems. One further potential reason for the lack of clarity regarding definitions and the change in the use of terms over time could be related to funder and publication preferences. No comprehensive public health system frameworks were identified within the literature although there was significant emphasis on defining the essential roles and functions of public health. 
These are broad and consensus on essential functions is often absent between jurisdictions, which made comparisons challenging. Services not provided by healthcare systems are often taken up by public health, increasing pressures on already limited budgets. In addition, response to health emergencies appears to have largely been adopted by public health systems because they are most likely to possess the capacity and expertise to organise and respond to large-scale events or threats to health. We found that, while many components of public health systems fit under the governance, delivery and financial arrangements of traditional healthcare systems, there are noted differences, specifically related to the role of partnerships and communication within public health. Partnerships provided the structure for multi-sectoral collaboration and facilitated communication and information exchange to accomplish the core functions of public health. A proposed framework for public health systems is presented in this paper.

The argument is made that public health and healthcare share the common goal of supporting the health of individuals within populations. Integration, the intersection of public health and healthcare, is believed to bring the two systems closer together to provide seamless service delivery within the broader health system that better responds to the needs of both individuals and communities $[33,65]$. The challenge with developing these integrated health systems is determining how to best align financial, governance and delivery arrangements, ensuring both complementarity and positive health outcomes. As population health extends beyond the health system to include the political, environmental and societal contexts, as such, it is important to understand these larger contexts within which health systems operate [89]. The conceptualisation of the current fit of public health systems within health systems has two important ramifications. The first being that integration of healthcare and public health will be difficult at best given that the aims, governance, finance and service delivery are not often aligned. There would have to be significant incentives for integration to happen and even with that, there may not be a shared vision of health to drive collaboration between these systems. The second ramification is that public health will not be able to inform healthy public policies unless they have a seat at the decision-making table for policies outside of the public health realm. There may be arguments on both sides as to whether this is practical or desired, but the case can be made that population health, encompassing the broader social determinants of health, will not occur within the current paradigm and structures.

\section{Strengths and limitations}

The flexibility of the CIS approach allows for a broad sampling frame and iterative filling of conceptual gaps.
The BFF approach provides a structured approach to data analysis but also for change if a more applicable model is identified. The combination of these two qualitative approaches allowed for a broad research question in an area that is not well defined and helped bring a lot of data together in an efficient manner. The study was informed by a diverse team of experts in public health, health systems research and qualitative research methodology. The search strategy may not have captured all terms and concepts regarding public health systems. To try and mitigate this, a search string was developed with broad search terms to identify as much relevant literature as possible. Additionally, as the reviewed literature mainly covers the period from 2000 to 2016, the search strategy may not have captured all relevant documents such as recent institutional reports. While literature addressing health systems have origins before 2000, more recent documents were purposively sampled and prioritised in the document selection process as they would expectedly include earlier relevant works. This also presents an opportunity to review works after 2016, such as the 2018 report on the organisation and financing of public health services in Europe, and more recent documents that highlight the importance of improving population health through the Sustainable Development Goals (SDGs) [90, 91]. CIS requires constant reflexive analysis by the principal investigator and results may vary if another person were to replicate this study; however, the use of a priori codes was used to increase transparency. Finally, although public health systems from various countries were reviewed, almost all documents were from high-income countries, mostly originating from the United States and Canada. While some of the results may be equally relevant to systems outside of these Western contexts, the findings highlight the need for future research outside of these jurisdictions, for example, in low- and middle-income countries, particularly in light of the SDGs.

\section{Placing this work within the literature}

This study is a first attempt at defining a holistic public health systems framework and highlighting the differences and similarities between public health and healthcare system arrangements. We have specifically addressed a priority research theme proposed by Canadian and United States federal agencies, such as the Canadian Institutes of Health Research Institute of Population and Public Health, the Centers for Disease Control and Prevention, and other stakeholders, to describe dimensions of public health systems and conceptualise a framework for public health systems.

\section{Practice and policy implications}

This study suggests five considerations for practice and policy. First, defining public health systems solidifies and challenges public health's role to encourage political 
interest to secure the investment necessary to improve health system capacity. The COVID-19 pandemic has demonstrated the importance of understanding the role of public health within the larger health system, particularly with respect to the capacity to respond to public health crises efficiently and effectively. As was observed following the 2004 SARS pandemic, it is expected that there will be an increase in renewed calls and discussion around public health systems strengthening. Second, the discourse around establishing essential functions of public health is enhanced. Our synthesis has identified a growing concern that public health is currently filling gaps within the healthcare system by providing clinical services to targeted or vulnerable groups, consuming vast amounts of both human and financial resources from already underresourced public health systems [5, 60, 69]. Thus, defining public health and the boundaries of public health systems could be an important step towards measuring performance and preventing public health systems from becoming too overburdened from the increasing scope of public health clinical activities $[48,54]$. Third, this study has reinforced the importance of partnerships in the work of public health. Partnerships have the potential to form and navigate systems in contexts challenged by limited resources. For example, the United Nations Millennium Development Goals, aimed to tackle societal issues influencing health, such as poverty, education, and gender equality and, while substantial progress was made, the state of many health systems revealed barriers to reaching specific targets and delivering services to the most vulnerable, particularly for those in many low- and middleincome countries. The SDGs, whose agenda is broader and more ambitious, explicitly recognise the broader determinants of health, by establishing social, economic and environmental objectives such as climate action, sustainable cities and communities, economic development, and social inclusion [92]. Defining public health systems serves as a building block for under-developed or transitioning public health systems and services, whereby determining roles and functions of public health systems allows practitioners to identify areas that require strengthening. Fourth, this synthesis suggests that the critical differences between public health and healthcare systems need to be acknowledged and negotiated for integration to be successful. The gaps that exist between the public health and healthcare subsystems have been highlighted. Lastly, the idea that public health is the champion of population health is presented as a challenge. Population health is influenced by political and social factors outside of the public health system. The idea of public health as the steward of population health requires serious consideration, especially if public health continues to be excluded from the decision-making process and its role in protecting and promoting health is relegated to the background.

\section{Research implications}

By developing a method that combined the best aspects of two qualitative systematic review methods, CIS and BFF, we were able to bring substantial amounts of data together in a timely manner, while simultaneously testing and refining a well-known framework in a critical way. The use of other frameworks, such as the performance-based conceptual framework by Handler et al. [42], or an assessment framework identified by Martin-Moreno et al. [53], provide other ways to examine public health systems and could be a way to validate the findings of this study or illustrate different health system ideas. The performance of public health systems cannot be measured if definitions, functions and key components are not well defined. The numerous variations in terminology make it difficult to perform a comparative analysis of public health systems across jurisdictions. Similarly, the differences in defined functions, or a lack thereof, limits our ability to monitor quality indicators between systems. Furthermore, the lack of research in public health and public health systems hampers both interest and investment in public health and limits the development of recommendations for evidence-based practice. Further research is required to determine what integration might look like and at what systems levels integration might work best. This presents additional opportunities for future research, particularly with respect to the gaps highlighted within financial arrangements such as remunerating providers and incentivising consumers. Lastly, this study is a first attempt at trying to understand how public health systems have been conceptualised. A public health systems framework (Table 1) and conceptualisation of how public health currently fits within the larger health system (Fig. 2) are proposed and can be applied and tested in real life settings as well as used to guide further research and practice in public health systems.

\section{Conclusion}

The aim of this paper was to examine the literature on how public health systems have been defined and classified and to illustrate how current public health systems align within established conceptual frameworks for health systems. Defining the scope of public health systems is crucial to solidify public health's role as part of the larger health system and the degree to which public health and healthcare systems are different should be understood if public health is to be able to attend to its primary mandate within integrated health systems. While there is increased movement towards health systems focused on population health, specifically the increased focus on Health in All Policies and One Health, many gaps exist to reach those aims. 


\section{Supplementary information}

Supplementary information accompanies this paper at https://doi.org/10. 1186/s12961-020-00583-z.

Additional file 1. The initial search strategy and databases. Additional file 1 provides search strings and detailed database search strategy.

Additional file 2. Characteristics of documents reviewed for this study. Additional file 2 provides a description of the characteristics of the documents included in this study.

Additional file 3. Definitions of entities and systems. Additional file 3 provides the definitions found within the literature regarding public health and public health systems.

Additional file 4. Public Health Functions and Purpose. Additional file 4 provides a table as a way of organising what functions were found within the literature across a variety of countries, following the three core public health functions and 10 essential services.

Additional file 5. Aligning public health systems into the health system arrangements framework. This additional file includes a summary of the coded data sources used to align public health within the health system arrangements framework.

\section{Abbreviations}

BFF: Best-fit framework synthesis; CIS: Critical interpretive synthesis; SDGs: Sustainable Development Goals

\section{Acknowledgements}

We would like to acknowledge Dr. Steven J. Hoffman for his input on an earlier version of this manuscript.

\section{Authors' contributions}

T. Jarvis and E. Alvarez conceived and designed the presented study. E. Alvarez, F. Scott and F. El-Jardali verified the analytical methods. T. Jarvis extracted, analysed and interpreted the data. E. Alvarez supervised the findings of this work. All authors discussed the results and contributed to the final manuscript. The author(s) read and approved the final manuscript.

\section{Authors' information}

This work was completed as part of a Master's thesis and includes material from a thesis published on MacSphere: http://hdl.handle.net/11375/22170. Jarvis, T. (2017). Defining public health systems: A critical interpretive synthesis of how public health systems are defined and classified (Master's dissertation)

\section{Funding}

Not applicable.

\section{Availability of data and materials}

All data generated or analysed during this study are included in this published article and its additional files.

\section{Ethics approval and consent to participate}

Not applicable.

\section{Consent for publication}

Not applicable.

\section{Competing interests}

The authors declare that they have no competing interests.

\section{Author details}

${ }^{1}$ Department of Health Research Methods, Evidence and Impact (HEI), McMaster University, 1280 Main Street West, Hamilton, ON L8S 4K1, Canada.

${ }^{2}$ Faculty of Health Sciences, American University of Beirut, Beirut, Lebanon.
Received: 13 January 2020 Accepted: 27 May 2020

Published online: 16 June 2020

\section{References}

1. Levesque J-F, Bergeron P, Roy DA. The interaction of public health and primary care: functional roles and organizational models that bridge individual and population perspectives. Public Health Rev. 2013:35(1):1.

2. Moloughney BW. The renewal of public health in Nova Scotia: building a public health system to meet the needs of Nova Scotians: Health Promotion and Protection; 2006. http://novascotia.ca/dhw/publichealth/ documents/Renewal-of-Public-Health-Report.pdf. Accessed 7 June 2020.

3. Scutchfield FD, Ingram RC. Public health systems and services research: building the evidence base to improve public health practice. Public Health Rev. 2013;8:35.

4. Lozon JC, Alikhan LM. Canada's public health system: is the pace of progress sufficient? Healthc Pap. 2007;7(3):52-9.

5. Kruk ME. Emergency preparedness and public health systems lessons for developing countries. Am J Prev Med. 2008;34(6):529-34.

6. Guyon A, Hancock T, Kirk M, MacDonald M, Neudorf C, Sutcliffe P, et al. The weakening of public health: a threat to population health and health care system sustainability. Can J Public Health. 2017;108(1):e1-6.

7. Scutchfield FD, Marks JS, Perez DJ, Mays GP. Public Health Services and Systems Research. Am J Prev Med. 2007;33(2):169-71.

8. Guyon A, Perreault R. Public health systems under attack in Canada: evidence on public health system performance challenges arbitrary reform. Can J Public Health. 2016:107(3):e326-9.

9. Breton M, Denis J-L, Lamothe L. Incorporating public health more closely into local governance of health care delivery: lessons from the quebec experience. Can J Public Health. 2010;101(4):314-7.

10. Kaluzny AB, Halverson PK, Miller CA, Fried B, Schenck SE, Richards TB. Performing public health functions: the perceived contribution of public health and other community agencies. J Health Hum Serv Adm. 1996;18: 288-303.

11. Moloughney BW. Public health medicine, public health practice, and public health systems. Can J Public Health. 2013;104(2):e115-6.

12. Beitsch L, Brooks R, Menachemi N, Libbey PM. Public health at center stage: new roles, old props. Health Aff. 2006;25(4):911-22.

13. Shakarishvili G, Atun R, Berman P, Hsiao W, Burgess C, Lansang MA. Converging health systems frameworks: towards a concepts-to-actions roadmap for health systems strengthening in low and middle income countries. Glob Health Gov. 2010;3(2):1-17.

14. Hoffman, Røttingen J-A, Bennett S, Lavis JN, Edge JS, Frenk J. A review of conceptual barriers and opportunities facing health systems research to inform a strategy from the World Health Organization. Geneva: Alliance HPSR, WHO; 2012

15. Di Ruggiero E, Frank J, Moloughney B. Strengthen Canada's public health system now. Can J Public Health. 2004;95(1):5.

16. Lenaway D, Halverson P, Sotnikov S. Public health systems research: setting a national agenda. Am J Public Health. 2006;96(3):410-3.

17. Carroll C, Booth A, Cooper K. A worked example of "best fit" framework synthesis: a systematic review of views concerning the taking of some potential chemopreventive agents. BMC Med Res Methodol. 2011;11:29. https://doi.org/10.1186/1471-2288-11-29.

18. Kastner M, Tricco AC, Soobiah C, Lillie E, Perrier L, Horsley T, et al. What is the most appropriate knowledge synthesis method to conduct a review? Protocol for a scoping review. BMC Med Res Methodol. 2012;12:114.

19. Dixon-Woods M, Cavers D, Agarwal S, Annandale E, Arthur A, Harvey J, et al. Conducting a critical interpretive synthesis of the literature on access to healthcare by vulnerable groups. BMC Med Res Methodol. 2006;6:35.

20. Carroll C, Booth A, Leaviss J, Rick J. 'Best fit' framework synthesis: refining the method. BMC Med Res Methodol. 2013:13:37.

21. Moher D, Liberati A, Tetzlaff J, Altman DG, The PRISMA Group. Preferred Reporting Items for Systematic Reviews and Meta-Analyses: The PRISMA Statement. PLOS Med. 2009;6(7):e1000097. https://doi.org/10.1371/journal. pmed.1000097.

22. World Health Organization. Everybody's business: strengthening health systems to improve health outcomes: WHO's framework for action. Geneva: WHO; 2007

23. Framework. The Merriam-Webster.com Dictionary. http://www.merriamwebster.com/dictionary/framework. Accessed 7 June 2020. 
24. Model. The Merriam-Webster.com Dictionary. https://www.merriam-webster. com/dictionary/model. Accessed 7 June 2020

25. Classification. The Merriam-Webster.com Dictionary. http://www.merriamwebster.com/dictionary/classification. Accessed 7 June 2020.

26. Barnett-Page $E$, Thomas J. Methods for the synthesis of qualitative research: a critical review. BMC Med Res Methodol. 2009;9:59.

27. Lavis JN, Røttingen J-A, Bosch-Capblanch X, Atun R, El-Jardali F, Gilson L, et al. Guidance for evidence-informed policies about health systems: linking guidance development to policy development. PLoS Med. 2012;9(3): e1001186.

28. Ciapponi A, Lewin S, Herrera CA, Opiyo N, Pantoja T, Paulsen E, et al. Delivery arrangements for health systems in low-income countries: an overview of systematic reviews. Cochrane Database Syst Rev. 2017;9(9): CD011083 http://doi.wiley.com/10.1002/14651858.CD011083.pub2.

29. Alvarez E, Lavis JN, Brouwers M, Schwartz L. Developing a workbook to support the contextualisation of global health systems guidance: a case study identifying steps and critical factors for success in this process at WHO. Health Res Policy Syst. 2018;16:19.

30. Alvarez E, Lavis JN, Brouwers M, Carmona Clavijo G, Sewankambo N, Solari $L$, et al. Developing evidence briefs for policy: a qualitative case study comparing the process of using a guidance-contextualization workbook in Peru and Uganda. Health Res Policy Syst. 2019;17:89. https://doi.org/10. 1186/s12961-019-0488-0.

31. Dey I. Qualitative data analysis: a user-friendly guide for social scientists. London; New York: Routledge; 1993.

32. Public Health Agency of Canada. Learning from SARS: renewal of Public Health in Canada: Health Canada; 2004. http://www.phac-aspc.gc.ca/ publicat/sars-sras/naylor/3-eng.php. Accessed 7 June 2020.

33. White F. Primary health care and public health: foundations of universal health systems. Med Princ Pract. 2015;24(2):103-16.

34. Ministry of Health and Long-Term Care. Initial Report on Public Health. Ministry of Health and Long-Term Care. Ontairo; 2009. https://collections.ola. org/mon/23008/295012.pdf. Accessed 7 June 2020.

35. Knight TM, Birt CA, Bocsan I, Armitage LE. The public health function in central and eastern Europe. Public Health. 2003;117(2):98-105.

36. Alwan A, Puska P, Siddiqi S. Essential public health functions for countries of the Eastern Mediterranean Region: what are they and what benefits do they offer? East Mediterr Health J. 2015;21(12):859-60.

37. Moore S, Mawji A, Shiell A, Noseworthy T. Public health preparedness: a systems-level approach. J Epidemiol Community Health. 2007;61(4):282-6.

38. Wall S. Transformations in public health systems. Health Aff. 1998;17(3):64-80

39. Allin S, Mossialos E, McKee M, Holland WW, World Health Organization. Making decisions on public health: a review of eight countries. Copenhagen: WHO Regional Office for Europe; 2004.

40. Centers for Disease Control and Prevention. Public health's infrastructure: a status report. Bethesda: Department of Health and Human Services; 2001.

41. Ellison JH. National Public Health Performance Standards: are they a means of evaluating the local public health system? J Public Health Manag Pract. 2005;11(5):433-6.

42. Handler A, Issel M, Turnock B. A conceptual framework to measure performance of the public health system. Am J Public Health. 2001;91(8):1235-9.

43. Hunter D. The state of the public health system in England. Public Health. 2008;122(10):1042-6.

44. Hyde JK, Shortell SM. The structure and organization of local and state public health agencies in the U.S. Am J Prev Med. 2012;42(5):S29-41.

45. Mays GP, Scutchfield FD, Bhandari MW, Smith SA. Understanding the organization of public health delivery systems: an empirical typology. Milbank Q. 2010;88(1):81-111.

46. Mays GP, Smith SA, Ingram RC, Racster $L$, Lamberth CD, Lovely ES. Public health delivery systems evidence, uncertainty, and emerging research needs. Am J Prev Med. 2009;36(3):256-65.

47. Roper WL, Baker EL, Dyal W, Nicola R. Strengthening the public health system. Public Health Rep. 1992;107(6):609-15.

48. Scutchfield FD, Miron E, Ingram RC. From service provision to function based performance - perspectives on public health systems from the USA and Israel. Isr J Health Policy Res. 2012;1:46.

49. Wholey DR, Gregg W, Moscovice I. Public health systems: a social networks perspective. Health Serv Res. 2009;44(5):1842-62.

50. Welton WE, Kantner TA, Katz SM. Developing tomorrow's integrated community health systems: a leadership challenge for public health and primary care. Milbank Q. 1997;75(2):261-88.
51. Centers for Disease Control and Prevention. Changes in the public health system. MMWR Morb Mortal Wkly Rep. 1999;48(50):1141-7.

52. Halverson PK, Berkowitz B. Public health finance: a conceptual framework. J Public Health Manag Pract. 2004;10(5):377-82.

53. Martin-Moreno JM, Harris M, Jakubowski E, Kluge H. Defining and assessing public health functions: a global analysis. Annu Rev Public Health. 2016;37: 335-55.

54. Mays GP, McHugh M, Shim K, Perry N, Halverson PK, Lenaway D, et al. Identifying dimensions of performance in local public health systems: results from the National Public Health Performance Standards Program. J Public Health Manag Pract. 2004;10(3):193-203.

55. Moulton AD, Baker EL, Blumenstock JS, Jensen J, Morris RD. Building the legal foundation for an effective public health system. J Law Med Ethics. 2002;30(3):48-51.

56. Zahner SJ. Local public health system partnerships. Public Health Rep. 2005; 120(1):76-83.

57. Lavis JN, editor. Ontario's health system: key insights for engaged citizens, professionals and policymakers. Hamilton: McMaster Health Forum; 2016.

58. World Health Organization. Essential public health functions: a three-country study in the Western Pacific Region. Geneva: WHO; 2003. https://iris.wpro. who.int/handle/10665.1/5437. Accessed 12 June 2020

59. Potter M, Fitzpatrick T. State funding for local public health: observations from six case studies. J Public Health Manag Pract. 2007;13(2):163-8.

60. Beitsch L, Grigg M, Menachemi N, Brooks R. Roles of local public health agencies within the state public health system. J Public Health Manag Pract. 2006;12(3):232-41.

61. Sutcliffe PA, Deber RB, Pasut G. Public health in Canada: a comparative study of six provinces. Can J Public Health. 1997;88(4):246-9.

62. Regan S, MacDonald M, Allan DE, Martin C, Peroff-Johnston N. Public health human resources: a comparative analysis of policy documents in two Canadian provinces. Hum Resour Health. 2014;12:13-24.

63. Kothari A, Edwards N. Who is Protecting the Canadian Public Health System? Home Health Care Manag Pract. 2003;15(5):391-8.

64. Das Gupta M, Rani M. India's public health system: how well does it function at the national level? In: World Bank Policy Research Working Paper No. 3447; 2004. https://papers.ssrn.com/sol3/papers.cfm?abstract_id=625325. Accessed 7 June 2020.

65. Williams D. Infectious diseases prevention and control in Ontario: continuing the investment in public health in 2008. Ministry of Health and Long-Term Care; 2008. https://collections.ola.org/ser/258918/2008.pdf. Accessed 7 June 2020.

66. Taylor G. The chief public health officer's report on the state of public health in Canada, 2014: public health in the future: Public Health Agency of Canada; 2014. http://publichealth.gc.ca/CPHOReport. Accessed 7 June 2020.

67. Lenihan P. The public health system: an idea whose time has come. J Public Health Manag Pract. 2005;11(2):165-7.

68. Beitsch L, Brooks R, Grigg M, Menachemi N. Structure and functions of state public health agencies. Am J Public Health. 2006;96(1):167-72.

69. Fooks C, Maslove L. A public health wake-up call for Canada. Health Policy Monit. 2003.

70. Madamala K, Sellers K, Beitsch LM, Pearsol J, Jarris PE. Structure and functions of state public health agencies in 2007. Am J Public Health. 2011;101(7):1179-86.

71. Parker AM, Shelton SR, Morganti KG, Nelson C. Assessing relationships between state and local public health organizations: evidence from the NACCHO 2008 profile of local health departments. J Public Health Manag Pract. 2012;18(2):156-9.

72. Fielding J, Luck J, Tye G. Reinvigorating public health core functions: restructuring Los Angeles county's public health system. J Public Health Manag Pract. 2003;9(1):7-15.

73. Basrur S. Building the foundation of a strong public health system for Ontarians. Ministry of Health and Long-Term Care; 2005. https://collections. ola.org/ser/258918/2005.pdf.

74. Hunter M, Hunter JC, Yang JE, Crawley AW, Aragon TJ. Public health system response to extreme weather events. J Public Health Manag Pract. 2016; 22(1):E1-10.

75. Guyon A. Canada's public health systems: Quebec. CPHA-PHPC webinar on Canadian Public Health Systems. Vancouver; 2015. https://www.cpha.ca/ canadas-public-health-system. Accessed 10 June 2020.

76. Baird J, Carlson K. National Public Health Performance Standards Assessment: first steps in strengthening North Dakota's public health system. J Public Health Manag Pract. 2005;11(5):422-7. 
77. Ministry of Health and Long-Term Care. Standards for public health programs and services: consultation document. Ontario: Ministry of Health and Long-Term Care; 2017.

78. Mays GP, Scutchfield FD. Improving public health system performance through multiorganizational partnerships. Prev Chronic Dis. 2010;7(6):A116.

79. Sofaer S. Challenges for the public in negotiating the health system in the 21st century. J Urban Health. 1999;76(2):211-28.

80. Rodriguez HP, Chen J, Owusu-Edusei K, Suh A, Bekemeier B. Local public health systems and the incidence of sexually transmitted diseases. Am J Public Health. 2012;102(9):1773-81,

81. Moore D, Shiell A, Noseworthy T, Russell M, Predy G. Public health preparedness in Alberta: a systems-level study. BMC Public Health. 2006;6:313.

82. Carlson V, Chilton MJ, Corso LC, Beitsch LM. Defining the functions of public health governance. Am J Public Health. 2015;105:S159-66.

83. Griffiths $\mathrm{S}$, Jewell T, Donnelly P. Public health in practice: the three domains of public health. Public Health. 2005;119(10):907-13.

84. Padgett S, Bekemeier B, Berkowitz B. Collaborative partnerships at the state level: promoting systems changes in public health in infrastructure. J Public Health Manag Pract. 2004;10(3):251-7.

85. Canadian Coalition for Public Health in the 21st Century. Consultation on strengthening the Pan-Canadian public health system and meeting with the Minister of State (public health). Can J Public Health. 2004:95(4):1-15.

86. Hunter D, Marks L, Smith K. The public health system in England: a scoping study. 2007. https://core.ac.uk/download/pdf/28964369.pdf. Accessed 7 June 2020.

87. Ståhl T, Wismar M, Ollila E, Lahtinen E, Leppo K. Health in all policies. Prospects and potentials. Geneva: European Observatory of Health Systems and Policies; 2006

88. Destoumieux-Garzón D, Mavingui P, Boetsch G, Boissier J, Darriet F, Duboz $P$, et al. The one health concept: 10 years old and a long road ahead. Front Vet Sci. 2018;5. https://doi.org/10.3389/fvets.2018.00014.

89. Fleck F. Randall Packard: learning to learn from global health history. Bull World Health Organ. 2018;96(4):231-2

90. Byskov J, Maluka S, Marchal B, Shayo EH, Blystad A, Bukachi S, et al. A systems perspective on the importance of global health strategy developments for accomplishing today's sustainable development goals. Health Policy Plann. 2019;34(9):635-45.

91. Rechel B, Jakubowski E, McKee M, Nolte E, editors. Organization and financing of public health services in Europe. Copenhagen: WHO Regional Office for Europe; 2018

92. United Nations. Transforming our world: the 2030 Agenda for sustainable development. Sustainable Development Knowledge Platform. https:// sustainabledevelopment.un.org/?menu=1300. Accessed 7 June 2020.

\section{Publisher's Note}

Springer Nature remains neutral with regard to jurisdictional claims in published maps and institutional affiliations.

Ready to submit your research? Choose BMC and benefit from:

- fast, convenient online submission

- thorough peer review by experienced researchers in your field

- rapid publication on acceptance

- support for research data, including large and complex data types

- gold Open Access which fosters wider collaboration and increased citations

- maximum visibility for your research: over $100 \mathrm{M}$ website views per year

At $\mathrm{BMC}$, research is always in progress.

Learn more biomedcentral.com/submissions 